Revista Brasileira de Farmacognosia Brazilian Journal of Pharmacognosy 22(2): 350-358, Mar./Apr. 2012

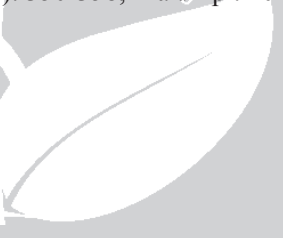

Article

Received 6 May 2011

Accepted 1 Jun 2011

Available online 5 Dec 2011

Keywords:

antibacterial

antioxidant

Coreopsis tinctoria

fatty acids

volatile compounds

ISSN 0102-695X

http://dx.doi.org/10.1590/S0102-

$695 \times 2011005000224$

\section{Metabolic and biological prospecting of Coreopsis tinctoria}

\author{
Luís Gaspar, ${ }^{1}$ Andreia P. Oliveira, ${ }^{1}$ Luís R. Silva, ${ }^{1}$ Paula B. \\ Andrade, ${ }^{1}$ Paula Guedes de Pinho, ${ }^{2}$ João Botelho, ${ }^{1}$ Patrícia \\ Valentão $^{*}, 1$
}

${ }^{I}$ REQUIMTE/Laboratório de Farmacognosia, Departamento de Química, Faculdade de Farmácia, Universidade do Porto, Portugal,

${ }^{2}$ REQUIMTE/Laboratório de Toxicologia, Departamento de Ciências Biológicas, Faculdade de Farmácia, Universidade do Porto, Portugal.

\begin{abstract}
Coreopsis tinctoria Nutt., Asteraceae, flowering tops infusion has been traditionally used in many countries to control hyperglycaemia. In this work we report for the first time fatty acids and volatile compounds in this species. Fifteen fatty acids and sixteen volatile compounds were determined by GC-ITMS, being saturated fatty acids and monoterpenes the main compounds. The antioxidant and antibacterial potential of this matrix was checked for the first time by several in vitro assays. A concentration-dependent activity was noticed against DPPH, nitric oxide and superoxide radicals. Antibacterial capacity was assessed against Gram-positive and Gram-negative bacteria, being more effective against the first. Additionally, acetylcholinesterase and butyrylcholinesterase inhibitory activity was also evaluated, but no effect was found. Our results provide evidence of a wide diversity of compounds with several biological properties, improving the knowledge on this poorly studied matrix, which can lead to an increment of the use of C. tinctoria flowering tops, namely in food and pharmaceutical applications.
\end{abstract}

\section{Introduction}

The use of plants to treat or prevent several diseases is in the basis of many traditional treatments. Additionally, they are regarded as important sources of essential nutrients and health -beneficial components that are crucial for human life, such as vitamins, minerals, phenolic compounds, volatiles and fatty acids (Grusak, 2002). The importance of fatty acids in plants lies on the fact that they constitute signal molecules, energy storage, and protect plants from environmental and biological stress (Ohlrogge, 1997). In the human organism fatty acids act like hormones or their precursors, help the digestion process and are a source of metabolic energy (Burtis \& Ashwood, 1996).

Plants show a constitutive emission of volatile compounds that are released from the surface and/or accumulated in storage sites. These compounds usually have low molecular weight and can be derived from amino acids, fatty acids and carbohydrates (Schwab et al., 2008). Apart from their involvement in insect/plant interaction, volatiles are also important for human health (Dudareva et al., 2004, Schwab et al., 2008). It is well known that some volatiles can protect against oxidation, or cellular damage caused by reactive species, preventing the initiation of several diseases, such as many types of cancer and neurodegenerative illnesses (Wei et al., 2001).
In recent years there has been an increasing search in natural compounds able to inhibit the action of cholinesterases for Alzheimer's disease (AD) treatment. $\mathrm{AD}$ is a neurodegenerative disorder of the central nervous system characterized by profound memory impairment, emotional disturbance, and, in late stages, by personality changes (Houghton et al., 2006). Furthermore, the exploitation of novel antimicrobial agents from plants has been of great interest too. Medicinal plants contain a large number of primary and secondary metabolites that are known to retard or inhibit the growth of bacteria, yeasts and molds (Burt \& Reinders, 2003; Chorianopoulos et al., 2008; Taveira et al., 2010).

Coreopsis tinctoria Nutt., Asteraceae, is native from North America, but it has spread worldwide. Its flowering tops infusion has been traditionally used in many countries to control hyperglycaemia (D'Oliveira Feijão, 1973). Despite this, C. tinctoria flowering tops constitute a poorly studied matrix. Only recently few studies have correlated its chemical composition with the promotion of glucose tolerance (Dias et al., 2010a; Dias et al., 2010b). So far, C. tinctoria flowering tops have been reported to contain flavonoids, namely chalcones (Shimokoriyama, 1957), aurones (Shimokoriyama, 1957), anthocyanins (Shimokoriyama, 1957), flavanones (Shimokoriyama, 1957) and flavonols (Dias et al., 2010a), as well as phenylpropanoids (Dias et al., 2010a, Shimokoriyama, 
1957, Reichling \& Thron, 1989).

Thus, this work aims to improve the knowledge on the metabolic profile of this species and on its biological potential. Following these purposes, the determination of fatty acids and volatile compounds was pursued. Additionally, antioxidant capacity, acetylcholinesterase (AChE) and butyrylcholinesterase (BuChE) inhibitory capacities and antibacterial activity against Gram-positive and Gram-negative bacteria were evaluated by in vitro assays.

\section{Material and Methods}

\section{Plant material}

The dried flowering tops of Coreopsis tinctoria Nutt., Asteraceae, were from a medicinal plants distributor (Morais e Costa \& C. ${ }^{\text {a }}$ Lda, Portugal). The identity was checked by the authors following the characteristics described in the Portuguese Flora (Coutinho, 1939). The acquired sample was also compared with an individual occurring in nature. The plant material was powdered (mean particle size lower than $910 \mu \mathrm{m}$ ). Voucher specimen was deposited at Laboratório de Farmacognosia, Faculdade de Farmácia, Universidade do Porto (CTF-LG-102010).

\section{Standards and reagents}

All chemicals used were of analytical grade. The standard compounds were purchased from various suppliers: $\alpha$-thujone, $\alpha$-pinene, bornyl acetate and benzaldehyde were from Sigma-Aldrich (St. Louis, MO, USA), fatty acid methyl esters kit and camphene were purchased from Supelco (Bellafonte, PA, USA), methyl jasmonate (internal standard), $\beta$-caryophyllene, $\beta$-caryophyllene epoxide, $\beta$-terpineol, $\quad$ cis-carveol, trans-carveol and myrtenal were from SAFC (St. Louis, USA) and borneol, carvone, verbenone, $\beta$-linalool and limonene were from Fluka (Buchs, Switzerland). 1,1Diphenyl-2-picrylhydrazyl $\quad\left(\mathrm{DPPH}^{\circ}\right), \quad \beta$-nicotinamide adenine dinucleotide (NADH), phenazine methosulphate (PMS), nitrotetrazolium blue chloride (NBT), 5,5'dithio-bis(2-nitrobenzoic acid) (DTNB), sulphanilamide, acetylcholinesterase (type VI-s, lyophilized powder) from electric eel (Electrophorus electricus), acetylthiocholine iodide (ATCI), butyrylcholinesterase from equine serum (lyophilized powder), S-butyrylthiocholine chloride and sodium nitroprusside dehydrate (SNP) were purchased from Sigma-Aldrich (St. Louis, MO, USA). N-(1-Naphthyl) ethylenediamine dihydrochloride, ethanol, potassium dihydrogen phosphate and ciprofloxacin were obtained from Merck (Darmstadt, Germany). Sodium sulphate anhydrous and isooctane were purchased from Panreac Química SA (Barcelona, Spain). Potassium hydroxide was from Pronalab (Lisboa, Portugal) and boron trifluoride
(BF3) 10\% methanol solution from Supelco (Bellafonte, PA, USA). Mueller Hinton Broth (MHB) and Mueller Hinton Agar (MHA) media were acquired to Liofilchem (Teramo, Italy).

\section{Plant extracts}

For a broader insight on the chemical composition of the species, two different extracts were assessed.

Aqueous extract

C. tinctoria dried flowering tops (1 g) was extracted with $200 \mathrm{~mL}$ of boiling water for $20 \mathrm{~min}$, with subsequent filtration and freezing. The extract was lyophilized and kept in a desiccator, in the dark. This extract was prepared as this plant is commonly consumed as infusion.

\section{Chloroform:methanol extract}

C. tinctoria dried flowering tops $(1.5 \mathrm{~g})$ was mixed with chloroform:methanol $(2: 1)(5 \times 150 \mathrm{~mL})$ with magnetic stirring $(500 \mathrm{rpm})$, for $10 \mathrm{~min}$, at $40{ }^{\circ} \mathrm{C}$. The resulting extract was then filtered through a Buchner funnel, under vacuum. Afterwards the extract was concentrated to dryness under reduced pressure $\left(40^{\circ} \mathrm{C}\right)$.

\section{Fatty acids}

\section{Derivatization}

C. tinctoria aqueous extract $(0.1 \mathrm{~g})$ was agitated with chloroform:methanol $(2: 1)(5 \times 10 \mathrm{~mL}, 500 \mathrm{rpm})$, for $10 \mathrm{~min}$, at $40^{\circ} \mathrm{C}$, concentrated to dryness under reduced pressure and redissolved in methanol. The organic extract prepared as described above was also redissolved in methanol. Fatty acids were determined as previously reported (Ribeiro et al., 2009). Hydrolysis was performed with $\mathrm{KOH}$ methanolic solution $(11 \mathrm{~g} / \mathrm{L})$, at $90{ }^{\circ} \mathrm{C}$, for $10 \mathrm{~min}$. The free fatty acids originally present and those resulting from the alkaline hydrolysis were derivatized to their methyl ester forms with $\mathrm{BF}_{3}$ methanolic solution $(10 \%)$, at $90^{\circ} \mathrm{C}$, for $10 \mathrm{~min}$. The methyl esters derivatives were extracted with isooctane and anhydrous sodium sulphate was added to assure the total absence of water. The resulting extracts were evaporated to dryness under a stream of nitrogen and redissolved in isooctane. The assays were performed in triplicate.

\section{GC-ITMS analysis}

The GC-ITMS analysis was performed according to Ribeiro et al. (2009) with some modifications. The oven temperature was set at $40{ }^{\circ} \mathrm{C}$ for $1 \mathrm{~min}$, then increasing 
$5{ }^{\circ} \mathrm{C} / \min$ to $250{ }^{\circ} \mathrm{C}$ and $3{ }^{\circ} \mathrm{C} / \min$ to $300{ }^{\circ} \mathrm{C} .1 \mu \mathrm{L}$ of the extract was analysed in Full Scan mode. Identification of compounds was achieved by comparison of their retention index and mass spectra with those from pure standards injected under the same conditions, with National Institute of Standards and Technology (NIST) MS 05 spectral database and with NIST Chemistry WebBook. The fatty acids methyl esters (FAME) quantification was achieved from the calibration curve of the respective FAME standards. The assays were performed in triplicate.

\section{Volatile compounds}

In order to obtain the most complete volatile profile, different extractive methods (solid-phase microextraction (SPME) and chloroform:methanol extraction) were used.

\section{SPME fibres}

Several commercial fibres can be used to extract volatiles. According to bibliography, recommendations of supplier (Supelco, Bellefonte, PA, USA) and to our own knowledge (Guedes de Pinho et al., 2009) the fibre used was coated with divinylbenzene/polydimethylsiloxane (DVB/PDMS), $65 \mu \mathrm{m}$.

\section{SPME)}

Headspace solid-phase microextraction (HS-

Flowering tops powder $(0.5 \mathrm{~g})$ and aqueous lyophilized extract $(0.2 \mathrm{~g})$ were stirred $(200 \mathrm{rpm})$ at $40^{\circ} \mathrm{C}$, for $10 \mathrm{~min}$. The fibre was then exposed to the headspace for $5 \mathrm{~min}$, without agitation at $40^{\circ} \mathrm{C}$. Afterwards the fibre was pulled into the needle sheath and the SPME device was removed from the vial and inserted into the injection port of the GC system for thermal desorption, for $1 \mathrm{~min}$. The fibre was then removed and conditioned in another $\mathrm{GC}$ injection port for $10 \mathrm{~min}$ at $250{ }^{\circ} \mathrm{C}$.

\section{GC-ITMS analysis}

The volatiles analysis was performed as mentioned in Guedes de Pinho et al. (2009), with some modifications. The injector port was heated to $220{ }^{\circ} \mathrm{C}$. Chloroform:methanol extract was redissolved in methanol and injected in split mode, with split ratio of $1 / 40$. The oven temperature was set at $40{ }^{\circ} \mathrm{C}$ (for $1 \mathrm{~min}$ ), then increased at $2{ }^{\circ} \mathrm{C} / \mathrm{min}$ to $88{ }^{\circ} \mathrm{C}$. Ionization was maintained off during the first $3 \mathrm{~min}$, to avoid solvent overloading. Covered mass ranged from $33-350 \mathrm{~m} / \mathrm{z}$, with a scan rate of $6 \mathrm{scan} / \mathrm{s}$. The injection volume was $1 \mu \mathrm{L}$ and the analysis was performed in Full Scan mode.

HS-SPME analysis of flowering tops powder and aqueous lyophilized extract was performed in Full Scan mode using the same equipment, under the same oven temperature conditions. The GC injector liner was a SPME specific one and the injection was done in splitless mode. Ionization was kept off for only $1 \mathrm{~min}$.

All compounds were identified by comparing their retention indices and mass spectra with those of authentic reference compounds injected under the same conditions, and with NIST 05 MS Library Database. Peaks' areas were determined by reconstructed FullScan chromatogram using for each compound some specific ions, quantification ions (Table 2). By this way some peaks which were co-eluted in FullScan mode (resolution value less than 1) could be integrated with a value of resolution higher than 1 . All samples were analyzed in triplicate.

\section{Antioxidant activity}

Aqueous lyophilized extract was used in the screening of antioxidant activity.

\section{$\mathrm{DPPH}^{\bullet}$ assay}

Antiradical activity was determined spectrophotometrically in a Multiskan Ascent plate reader (Thermo; electron corporation), by monitoring the disappearance of $\mathrm{DPPH} \bullet$ at $515 \mathrm{~nm}$, according to a described procedure (Oliveira et al., 2009).

\section{Nitric oxide assay}

The nitric oxide scavenging capacity was determined by using Griess reagent, in a Multiskan Ascent plate reader (Thermo; electron corporation), as before (Oliveira et al., 2009).

\section{Superoxide anion assay}

Superoxide was generated by the NADH/PMS system and the effect of the extract on radical-induced reduction of NBT was monitored spectrophotometrically in a Multiskan Ascent plate reader (Thermo, electron corporation), as reported in Oliveira et al. (2009).

\section{Hypochlorous acid assay}

The inhibition of hypochlorous acid-induced 5-thio-2-nitrobenzoic acid (TNB) oxidation to DTNB was evaluated spectrophotometrically in a Multiskan Ascent plate reader (Thermo, electron corporation), at $412 \mathrm{~nm}$, as previously reported (Vrchovská et al., 2006), with some modifications. The reaction mixtures in the sample wells consisted of $160 \mu \mathrm{L}$ of redissolved lyophilized extract, 260 $\mu \mathrm{L}$ of TNB and $180 \mu \mathrm{L}$ of hypochlorous acid solution. 
Acetylcholinesterase (AChE) and butyrylcholinesterase (BuChE) inhibitory activities

Aqueous lyophilized extract was used in the screening of cholinesterase inhibitory properties. The inhibition of AChE activity was determined spectrophotometrically in a Multiskan Ascent plate reader (Thermo Electron Corporation), based on Ellman's method, as previously reported (Oliveira et al., 2009). BuChE inhibition assay was performed in a similar way, using 25 $\mu \mathrm{L}$ of substrate (15 $\mathrm{mM}$ butyrylthiocholine chloride) and $25 \mu \mathrm{L}$ of $\mathrm{BuChE}(0.1 \mathrm{U} / \mathrm{mL})$.

\section{Antibacterial activity}

\section{Microorganisms}

Nine bacteria species were used: Staphylococcus aureus (ATCC 20231), Staphylococcus epidermidis (ATCC 20044), Micrococcus luteus (ATCC 20030), Enterococcus faecalis (ATCC 20477), Bacillus cereus (ATCC 31), Proteus mirabilis (ATCC 4479), Escherichia coli (ATCC 30083), Pseudomonas aeruginosa (ATCC 50071) and Salmonella typhimurium (ATCC 43971). All cultures were obtained from the Laboratory of Microbiology, Faculty of Pharmacy, Porto University, Portugal. Stock cultures were maintained on MHA at 4 ${ }^{\circ} \mathrm{C}$.

\section{Preparation of inocula}

Bacterial inocula were prepared by growing cells in MHB for $24 \mathrm{~h}$, at $37^{\circ} \mathrm{C}$. Cell suspensions were diluted in sterile MHB to provide initial cell counts of about $10^{6}$ colony-forming units per $\mathrm{mL}(\mathrm{CFU} / \mathrm{mL})$.

\section{Minimum inhibitory concentration (MIC)}

The minimum inhibitory concentration of $C$. tinctoria flowering tops extracts was assessed by the twofold serial dilution method, as described by Taveira et al. (2010). The plant extracts were redissolved in methanol $(5 \%, \mathrm{v} / \mathrm{v})$ and diluted in MBH. MIC were determined as the lowest concentration able to inhibit the visible growth of the tested culture.

\section{Results and Discussion}

\section{Fatty acids composition}

Fatty acids were present in both chloroform:methanol and aqueous lyophilized extracts (Table 1). Comparing both extracts, we can observe that chloroform:methanol is the one with higher diversity and fatty acids content (Table 1 and Figure 1), which is not surprising considering the low polarity of these compounds and, consequently, their higher affinity for the organic solvent. Fifteen fatty acids were identified, being distributed by saturated fatty acids (capric, lauric, myristic, pentadecanoic, palmitic, heptadecanoic, stearic, arachidic, heneicosanoic, behenic, tricosanoic and lignoceric acids), monounsaturated fatty acids (palmitoleic and oleic acids) and a polyunsaturated fatty acid (linolenic acid) (Table 1). As far as we know, this is the first report describing the fatty acid composition of C. tinctoria (Asteraceae) flowering tops.

This vegetal material is essentially constituted by saturated fatty acids (Table 1), unlike what happens with seeds, which were previously reported to mainly contain linoleic acid, a polyunsaturated fatty acid (C18:2) (Coxworth, 1965). Myristic was the major fatty acid, corresponding to $c a .26 .3$ and $29.6 \%$ of total fatty acids content in chloroform:methanol and aqueous lyophilized extracts, respectively (Table 1 ).

Palmitoleic was the only monounsaturated fatty acid present in the aqueous lyophilized extract and linolenic and oleic acids were found just in the chloroform:methanol extract (Table 1).

\section{Volatile profile}

Sixteen volatile compounds were identified in C. tinctoria flowering tops, being distributed by distinct chemical classes: 1 aldehyde, 13 monoterpenes and 2 sesquiterpenes, being monoterpenes the compounds present in highest amounts (Table 2 and Figure 2). As far as we know, this is the first study characterizing the volatile composition of this matrix. Comparing the two extracts and the powdered sample, we can observe that the flowering tops powder is characterized by higher diversity and content of volatile compounds and that the chloroform:methanol extract is the poorest one (Table 2). $\alpha$-Pinene ( $c a .45 .2 \%$ of total compounds area) and trans-carveol (ca. 28.6\%) were the volatiles present in higher amounts in C. tinctoria powder and aqueous lyophilized extract, respectively (Table 2). In the chloroform:methanol extract, carvone and cis-carveol were the major compounds, corresponding to $c a .35 .3$ and $34.8 \%$, respectively (Table 2). Amongst monoterpenes we can highlight the presence of $\alpha$-thujone, $\beta$-linalool, $\beta$-terpineol, borneol and bornyl acetate only in flowering tops powder. On the other hand, limonene was found just in chloroform:methanol extract which may be related with its higher affinity for the organic solvent.

$\beta$-Caryophyllene and its epoxide were detected only in the flowering tops powder (Table 2) and benzaldehyde was not found in the chloroform:methanol extract (Table 2). 
Table 1. Fatty acids composition of Coreopsis tinctoria flowering tops ( $\mathrm{mg} / \mathrm{kg}$ of dried plant).

\begin{tabular}{cclccc}
\hline & & \multicolumn{1}{c}{ Derivatized fatty acids } & $\mathrm{RI}^{\mathrm{b}}$ & Aqueous lyophilized extract & $\mathrm{CHCl}_{3}: \mathrm{MeOH}^{\mathrm{c}}$ extract \\
\hline 1 & C10:0 & Decanoic acid (capric acid) & 1348 & $9.3 \pm 0.5$ & $24.0 \pm 0.9$ \\
2 & C12:0 & Dodecanoic acid (lauric acid) & 1550 & $1.6 \pm 0.2$ & $279.2 \pm 23.5$ \\
3 & C14:0 & Tetradecanoic acid (myristic acid) & 1739 & $45.5 \pm 3.4$ & $554.2 \pm 11.7$ \\
4 & C15:0 & Pentadecanoic acid & 1835 & $2.3 \pm 0.3$ & $110.7 \pm 4.6$ \\
5 & C16:1 & cis-9-Hexadecenoic acid (palmitoleic acid) & 1909 & $1.5 \pm 0.1$ & $39.7 \pm 1.3$ \\
6 & C16:0 & Hexadecanoic acid (palmitic acid) & 1930 & $1.1 \pm 0.1$ & $23.2 \pm 2.2$ \\
7 & C17:0 & Heptadecanoic acid & 2026 & $30.3 \pm 2.1$ & $136.4 \pm 40.5$ \\
8 & C18:3 & cis-9,12,15-Octadecatrienoic acid (linolenic acid) & 2101 & nd & $53.9 \pm 0.3$ \\
9 & C18:1 & cis-9-Octadecenoic acid (oleic acid) & 2097 & nd & $97.6 \pm 7.7$ \\
10 & C18:0 & Octadecanoic acid (stearic acid) & 2112 & $2.8 \pm 0.2$ & $143.4 \pm 7.7$ \\
11 & C20:0 & Eicosanoic acid (arachidic acid) & 2282 & $4.2 \pm 0.1$ & $155.4 \pm 2.3$ \\
12 & C21:0 & Heneicosanoic acid & 2412 & $7.7 \pm 1.0$ & $45.1 \pm 0.7$ \\
13 & C22:0 & Docosanoic acid (behenic acid) & 2541 & $26.7 \pm 1.1$ & $214.5 \pm 18.6$ \\
14 & C23:0 & Tricosanoic acid & 2671 & $15.2 \pm 0.7$ & $88.1 \pm 2.1$ \\
15 & C24:0 & Tetracosanoic acid (lignoceric acid) & 2709 & $5.5 \pm 0.2$ & $142.1 \pm 7.1$ \\
& & Saturated Fatty Acids (SFA) & & 152.2 & 1916.3 \\
& & Monounsaturated Fatty Acids (MUFA) & & 1.5 & 137.3 \\
\hline
\end{tabular}

${ }^{\text {a}}$ Results are expressed as mean \pm standard deviation of three determinations; ${ }^{b} \mathrm{RI}=$ retention index of methyl esters fatty acids; ${ }^{\mathrm{c}} \mathrm{CHCl}: \mathrm{MeOH}$, chloroform/methanol; nd, not detected; $\sum$, sum of the determined fatty acids.

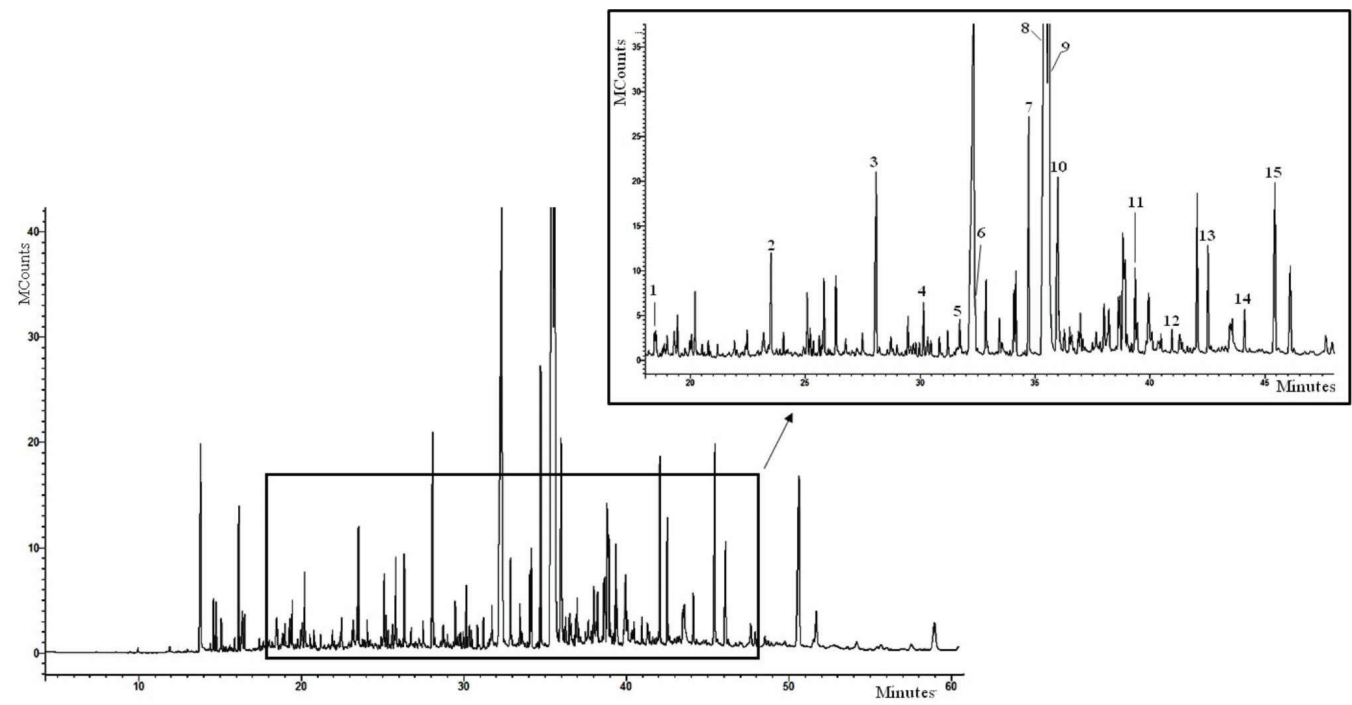

Figure 1. GC-ITMS fatty acids profile of Coreopsis tinctoria flowering tops chloroform:methanol extract. Full Scan: 1. Decanoic acid; 2. dodecanoic acid; 3. tetradecanoic acid; 4. pentadecanoic acid; 5. cis-9-hexadecenoic acid; 6. hexadecanoic acid; 7. heptadecanoic acid; 8. cis-9,12,15-octadecatrienoic acid; 9. cis-9-octadecenoic acid; 10. octadecanoic acid; 11. eicosanoic acid; 12. heneicosanoic acid; 13. docosanoic acid; 14. tricosanoic acid and 15. tetracosanoic acid.

Some of these compounds ( $\alpha$-pinene, limonene, $\beta$-caryophyllene, camphene and bornyl acetate) were reported to occur in Coreopsis genus, being already described in the essential oils of Coreopsis barteri and Coreopsis grandiflora leaves (Menut \& Lamaty, 1996).
The leaves of $C$. barteri contained mainly monoterpenes, as it happened with our matrix. On the other hand, $C$. grandiflora leaves were predominantly composed by sesquiterpenes (Menut \& Lamaty, 1996). 
Table 2. Volatile composition of Coreopsis tinctoria flowering tops.

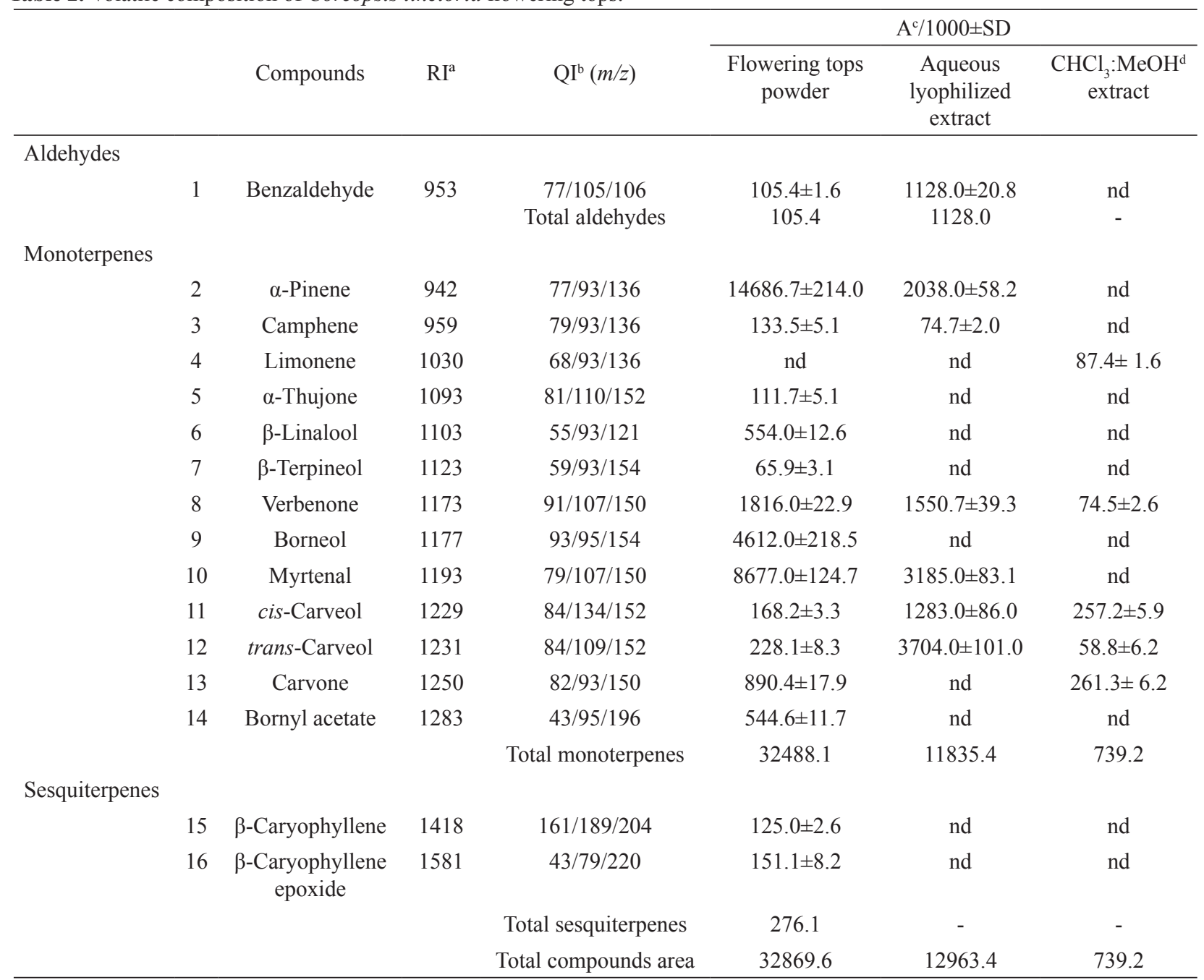

aRI: retention index; 'bI: quantification ions; ${ }^{\mathrm{c} A r e a}$ expressed as arbitrary units; SD: standard deviation of three assays; ${ }^{\mathrm{d}} \mathrm{CHCl}: \mathrm{MeOH}$, chloroform:methanol extract; nd: not detected.

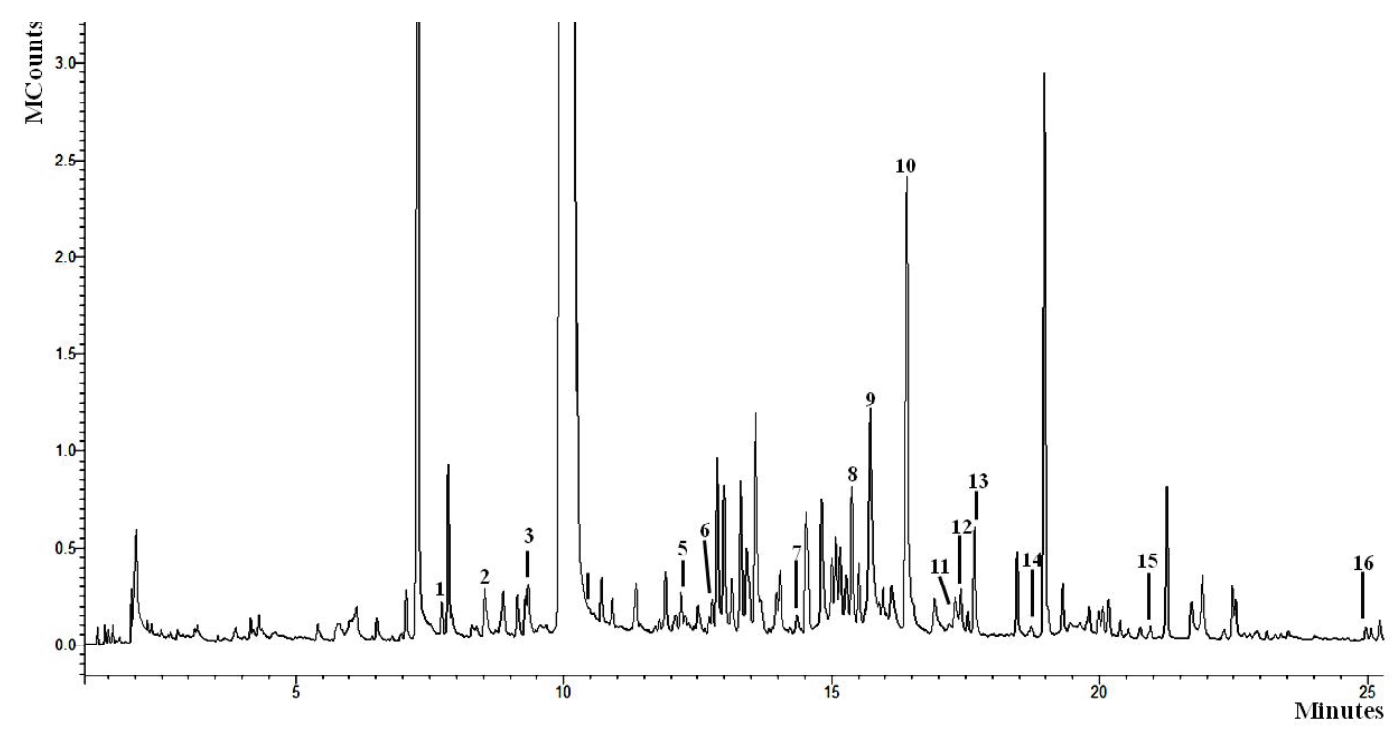

Figure 2. HS-SPME/GC-ITMS volatile profile of Coreopsis tinctoria flowering tops powder. Full Scan. 1. benzaldehyde; 2 . $\alpha$-pinene; 3. camphene; 5 . $\alpha$-thujone; 6. $\beta$-linalool; 7. $\beta$-terpineol; 8. verbenone; 9. borneol; 10. myrtenal; 11. cis-carveol; 12. trans-carveol; 13. carvone; 14 . bornyl acetate; 15 . $\beta$-caryophyllene and $16 . \beta$-caryophyllene epoxide. 
Biological potential

\section{Antioxidant activity}

In the present work, the antioxidant capacity of C. tinctoria aqueous lyophilized extract was screened by DPPH' assay, being observed a concentration-dependent effect (IC50 $0.041 \mathrm{mg} / \mathrm{mL}$ ) (Figure 3A).

C. tinctoria also displayed a protective effect against nitric oxide and superoxide radicals, in a concentration-dependent way, with IC50 values of 0.107 and $0.237 \mathrm{mg} / \mathrm{mL}$, respectively (Figures $3 \mathrm{~B}$ and $3 \mathrm{C}$ ). The inhibitory activity over these two radical species is of great importance, once it prevents the formation of other deleterious radicals, like peroxynitrite, which causes damage in cardiovascular and neurological systems and is also able to nitrosylate biomolecules, such as proteins (Beckman, 1996, Zubia et al., 2007, Pacher et al., 2007). C. tinctoria capacity for scavenging hypochlorous acid was also evaluated, but no effect was observed at the tested concentrations.

Overall, the results obtained in the three assays revealed $C$. tinctoria flowering tops' capacity to scavenge free radicals, which can be partially related to the presence of monoterpenes with known antioxidant properties, as $\alpha$-pinene (Singhara et al., 1998). Nevertheless, the existence in this species of other non-determined compounds, with antioxidant capacity, cannot be ignored.

\section{$\mathrm{AChE}$ and BuChE inhibitory activities}

One possible strategy for enhancing cholinergic activity in the brain is by the inhibition of $\mathrm{AChE}$ and BuChE, responsible for the cleavage of the neurotransmitter acetylcholine (Houghton et al., 2006). According to Houghton et al. (2006), compounds like terpenes have the capacity to inhibit these enzymes. C. tinctoria aqueous lyophilized extract presents a high content of monoterpenes, including $\alpha$-pinene, which is found at an amount reported to exert activity against AChE and BuChE (10-15\%) (Perry et al., 2000; Houghton et al., 2006). Despite this, no effect was observed. The absence of AChE and BuChE inhibitory activities may be due to the existence of interactions between the different compounds present in the tested aqueous extract, namely antagonisms.

\section{Antibacterial activity}

The chloroform:methanol and aqueous lyophilized extracts from $C$. tinctoria flowering tops were screened against Gram-positive ( $S$. aureus, S. epidermidis, $M$. luteus, E. faecalis and B. cereus) and Gram-negative (P. mirabilis, E. coli, $P$. aeruginosa and S. typhimurium) bacteria, allowing the determination of some MIC, which
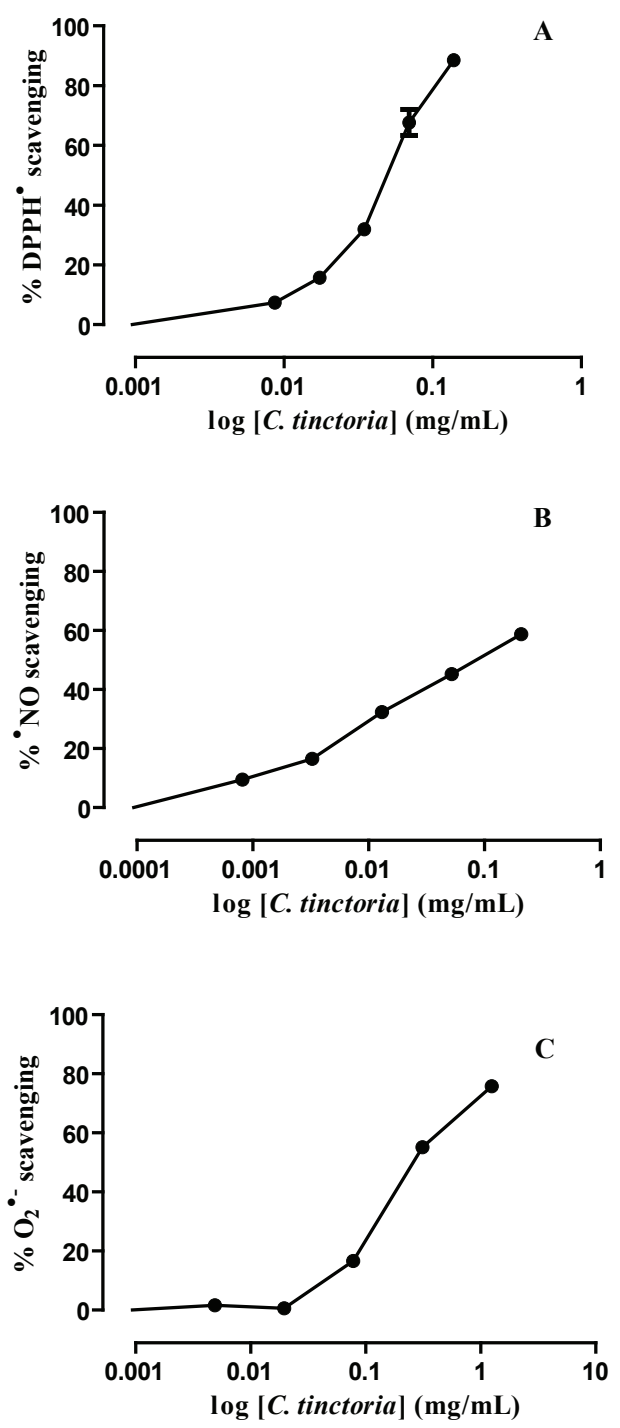

Figure 3. Effect of Coreopsis tinctoria flowering tops against (A) $\mathrm{DPPH}^{\circ}$, (B) nitric oxide ( $\left.{ }^{\circ} \mathrm{NO}\right)$ and (C) superoxide radical $\left(\mathrm{O}_{2}^{-}\right)$. Values show mean $\pm \mathrm{SE}$ of three experiments performed in triplicate.

are indicative of the antibacterial properties of this species (Table 3). Under the tested concentrations, Gram-positive bacteria were most susceptible to both tested extracts and, in a general way, chloroform:methanol seems to be the most effective one (Table 3). Previous studies indicated that Gram-positive bacteria appear to be more sensitive to the action of natural extracts (Dorman \& Deans, 2000; Taveira et al., 2010), which is in agreement with our results. These results can probably be related to the physical differences between the cell walls of Gram-positive and Gramnegative bacteria. The presence of the external membrane with high content of lipopolysaccharide surrounding the cell wall in Gram-negative bacteria is considered to be the major contributor to its ability to resist chemical stress (Nohynek et al., 2006). In a general way, E. faecalis and $B$. cereus were the most susceptible organisms. $E$. 
faecalis, a member of the healthy human intestinal flora, can cause several infections, especially in nosocomial environments (Shankar et al., 2002). B. cereus is a cause of food poisoning, which is frequently associated with the consumption of rice-based dishes. This organism produces an emetic or diarrheal syndrome induced by an emetic toxin and enterotoxin, respectively (Drobniewski, 1993).

Table 3. MIC of Coreopsis tinctoria flowering tops extracts against selected bacteria $(\mathrm{mg} / \mathrm{mL})$.

\begin{tabular}{lcc}
\hline \multicolumn{1}{c}{ Bacteria } & $\begin{array}{c}\mathrm{CHCl}_{3}: \mathrm{MeOH}^{\mathrm{a}} \\
\text { extract }\end{array}$ & $\begin{array}{c}\text { Aqueous } \\
\text { lyophilized extract }\end{array}$ \\
\hline Gram-positive & 15.6 & 18.1 \\
S. aureus & 31.3 & 9.1 \\
S. epidermidis & 3.9 & 72.6 \\
M. luteus & 2.0 & 4.5 \\
E. faecalis & 7.8 & 18.1 \\
B. cereus & & \\
Gram-negative & 31.3 & 72.6 \\
P. mirabillis & 125.0 & 72.6 \\
E. coli & 62.5 & $>72.6$ \\
P. aeruginosa & 31.3 & 36.3 \\
S. typhimurium & CHCl MeOH extract, chloroform:methanol extract.
\end{tabular}

${ }^{\mathrm{a}} \mathrm{CHCl}_{3}: \mathrm{MeOH}$ extract, chloroform:methanol extract.

C. tinctoria flowering tops' antibacterial activity may be due, at least partially, to the presence of fatty acids, which are well-known for their bactericidal potential (Kabara et al., 1972). Fatty acids and derivatives are more effective against Gram-positive than Gram-negative organisms (Sheu \& Freese, 1973). The mechanism of bactericidal action of long-chain fatty acids and derivatives is ascribed to a balance between the hydrophilic and hydrophobic parts of the molecule. Regardless of the polarity of the hydrophilic portion, optimum chain length is between $\mathrm{C}_{12}$ and $\mathrm{C}_{16}$ (Sheu \& Freese, 1973). In fact, $C$. tinctoria aqueous and chloroform:methanol extracts were characterized by high quantities of these kinds of compounds, which correspond to ca. 34 and $48 \%$ of their total fatty acids content, respectively. In addition, lauric acid $\left(\mathrm{C}_{12}\right)$, the second major fatty acid in the chloroform:methanol extract ( $c a .13 .2 \%$ of total fatty acids), is recognized by its high capacity to inhibit Grampositive bacteria (Kabara et al., 1972). Also the antibacterial action of long-chain unsaturated fatty acids, including oleic and linolenic acids $\left(\mathrm{C}_{18}\right)$, present in chloroform:methanol extract, is well known (Seidel \& Taylor, 2004).

Furthermore, this activity may also be related with the presence of volatile compounds. Among these, we can highlight the presence of carvone in the chloroform:methanol extract, of benzaldehyde, $\alpha$-pinene and myrtenal in the aqueous lyophilized one and of trans-carveol in both of them, which are known for their antimicrobial properties (Sivropoulou et al., 1995, Dewick, 1997, Baby et al., 2006, Kochi et al., 1980).

\section{Conclusion}

The fatty acids and volatile composition of $C$. tinctoria, Asteraceae, flowering tops, as well as their antioxidant and antibacterial activities were described for the first time, improving the knowledge of the metabolome and biological potential of the species. These results can contribute for an increment on the consumption of this matrix. Furthermore, C. tinctoria can be used in food industry as food preservative, or can be applied in cosmetic and pharmaceutical industries providing protection against several diseases.

\section{Acknowledgment}

APO (SFRH/BD/47620/2008) is indebted to Fundação para a Ciência e a Tecnologia (FCT) for the grant. The authors are grateful to FCT for grant no. PEst-C/ EQB/LA0006/2011.

\section{References}

Baby S, Mathew D, Nediyamparambu SP, Renju KV, Varughese $\mathrm{G}$ 2006. Composition and antimicrobial activity of essential oil from the fruits of Amomum cannicarpum. Acta Pharmaceut 56: 473-480.

Beckman JS 1996. Oxidative damage and tyrosine nitration from peroxynitrite. Chem Res Toxicol 9: 836-844.

Burt SA, Reinders RD 2003. Antibacterial activity of selected plant essential oils against Escherichia coli O157:H7. Lett Appl Microbiol 36: 162-167.

Burtis CA, Ashwood ER 1996. Tietz Fundamentals of Clinical Chemistry, 4th ed. Philadelphia: W.B. Saunders Company.

Chorianopoulos NG, Giaouris ED, Skandamis PN, Haroutounian SA, Nychas GJE 2008. Desinfectant test against monoculture and mixed-culture biofilms composed of technological, spoilage and pathogenic bacteria: bactericidal effect of essential oil and hydrosol of Satureja thymbra and comparison with standard acidbase sanitizers. J Appl Microbiol 104: 1586-1869.

Coutinho AXP 1939. Flora de Portugal: Plantas vasculares. Lisboa: Bertrand.

Coxworth ECM 1965. Oil and protein content, and oil composition of the seeds of some plants of the Canadian prairies. $\mathrm{J} \mathrm{Am}$ Oil Chem Soc 42: 891-894.

Dewick PM 1997. Medicinal Natural Products - A Biosynthetic Approach, 3rd ed. Chichester: John Wiley \& Sons Ltd.

Dias T, Bronze MR, Houghton PJ, Mota-Filipe H, Paulo A 2010a. The flavonoid-rich fraction of Coreopsis tinctoria promotes glucose tolerance regain through pancreatic function recovery in streptoxotocin-induced glucose- 
intolerant rats. J Ethnopharmacol 132: 483-490.

Dias T, Mota-Filipe H, Liu B, Jones P, Houghton PJ, Paulo A 2010b. Recovery of oral glucose tolerance by wistar rats after treatment with Coreopsis tinctoria infusion. Phytother Res 24: 699-705.

Drobniewski FA 1993. Bacillus cereus and related species. Clin Microbiol Rev 6: 324-338.

D'Oliveira Feijão R 1973. Medicina pelas Plantas. Lisboa: Livraria Progresso Editora.

Dorman HJD, Deans SG 2000. Antimicrobial agents from plants: antibacterial activity of plant volatile oils. $J$ Appl Microbiol 88: 308-316.

Dudareva N, Pichersky E, Gershenzon J 2004. Biochemistry of plant volatiles. Plant Physiol 135: 1893-1902.

Guedes de Pinho P, Gonçalves RF, Valentão P, Pereira DM, Seabra RM, Andrade PB, Sottomayor M 2009. Volatile composition of Catharanthus roseus (L.) G. Don using solid-phase microextraction and gas chromatography/ mass spectrometry. J Pharm Biomed Anal 49: 674-685.

Grusak MA 2002. Phytochemicals in plants: genomics-assisted plant improvement for nutritional and health benefits. Curr Opin Biotech 13: 508-511.

Houghton PJ, Ren Y, Howes MJ 2006. Acetylcholinesterase inhibitors from plants and fungi. Nat Prod Rep 23: 181199.

Kabara JJ, Swieczkowski DM, Conley AJ, Truant JP 1972. Fatty acids and derivatives as antimicrobial agents. Antimicrob Agents Ch 2: 23-28.

Kochi M, Takeuchi S, Mizutani T, Mochizutki K, Matsumoto Y, Saito Y 1980. Antitumor activity of benzaldehyde. Cancer Treat Rep 64: 21-23.

Menut C, Lamaty G 1996. Aromatic plants of tropical central Africa. Part XXVI. Volatile constituents of leaves of Coreopsis barteri Oliv. \& Hiern and Coreopsis grandiflora Hogg ex Sweet from Cameroon. Flavour Fragr J 11: 31-33.

Nohynek LJ, Alakomi HL, Kahkonen MP, Heinonen M, Helander KM, Oksman-Caldentey KM, Puupponen-Pimia RH 2006. Berry phenolics: antimicrobial properties and mechanisms of action against severe human pathogens. Nutr Cancer 54: 18-32.

Ohlrogge JB 1997. Regulation of fatty acids synthesis. Annu Rev Plant Phys 48: 109-136.

Oliveira AP, Valentão P, Pereira JA, Silva BM, Tavares F, Andrade PB 2009. Ficus carica L.: Metabolic and biological screening. Food Chem Toxicol 47: 2841-2846.

Pacher, P, Beckman J.S, Liaudet L. 2007. Nitric oxide and peroxynitrite in health and disease. Physiol Res 87: 315424.

Perry, NS, Houghton, PJ, Theobald A., Jenner P, Perry, EK 2000. In-vitro inhibition of human erythrocyte acetylcholinesterase by Salvia lavandulaefolia essential oil and constituent terpenes. J Pharm Pharmacol 52: 895-902.

Reichling J, Thron U 1989. Comparative study on the production and accumulation of unusual phenylpropanoids in plants and in vitro cultures of Coreopsis tinctoria and $C$. lanceolata. Pharm Weekblad 11: 83-86.

Ribeiro B, Guedes de Pinho P, Andrade PB, Baptista P, Valentão P 2009. Fatty acid composition of wild edible mushrooms species: a comparative study. Microchem J 93: 29-35

Schwab W, Davidovich-Rikanati R, Lewinsohn E 2008. Biosynthesis of plant-derived flavour compounds. Plant J 54: 712-732.

Seidel V, Taylor PW 2004. In vitro activity of extracts and constituents of Pelagonium against rapidly growing mycobacteria. Int J Antimicrob Ag 23: 613-619.

Singhara A, Macku C, Shibamoto T 1998. Antioxidative activity of brewed coffee extracts. In Functional Foods for Disease Prevention II: Medicinal Plants and Other Foods. Washington DC: American Chemical Society, p. 101-109.

Sivropoulou A, Kokkin S, Lanaras, T, Arsenakis M 1995. Antimicrobial activity of mint essential oils. J Agr Food Chem 43: 2384-2388.

Shankar N, Baghdayan AS, Gilmore MS 2002. Modulation of virulence within a pathogenicity island in vancomycinresistant Enterococcus faecalis. Nature 417: 746-750.

Sheu CW, Freese E 1973. Lipopolysaccharide layer protection of Gram-negative bacteria against inhibition by long-chain fatty acids. J Bacteriol 115: 869-875.

Shimokoriyama M 1957. Anthochlor pigments of Coreopsis tinctoria. J Am Chem Soc 79: 214-220.

Taveira M, Silva LR, Vale-Silva LA, Pinto E, Valentão P, Ferreres F, Guedes de Pinho P, Andrade PB 2010. Lycopersicon esculentum seeds: an industrial byproduct as an antimicrobial agent. J Agr Food Chem 58: 9529-9536.

Vrchovská V, Sousa C, Valentão P, Ferreres F, Pereira JA, Seabra RM, Andrade PB 2006. Antioxidative properties of tronchuda cabbage (Brassica oleracea L. var. costata DC) external leaves against DPPH, superoxide radical, hydroxyl radical and hypochlorous acid. Food Chem 98: 416-425.

Wei A, Mura K, Shibamoto T 2001. Antioxidative activity of volatile chemicals extracted from beer. J Agric Food Chem 49: 4097-4101.

Zubia M, Robledo D, Freile-Pelegrin Y 2007. Antioxidant activities in tropical marine macroalgae from the Yucatan Península, México. J Appl Phycol 19: 449-458.

\section{*Correspondence}

Patrícia Valentão

REQUIMTE/Laboratório de Farmacognosia, Departamento de Química, Faculdade de Farmácia, Universidade do Porto

R. Aníbal Cunha, 164, 4050-047 Porto, Portugal

valentao@ff.up.pt

Tel. +351222078934

Fax: +351222003977 